\title{
Temperatura de secagem da casca da cebola para obtenção de chá
}

\section{Drying temperature of the onion skin for making tea}

\author{
Aline Pacheco Albuquerque ${ }^{1}$, Deborah Evellyn Gomes Alves ${ }^{2}$, Ana Paula Trindade Rocha ${ }^{3}$, Gilmar Trindade Araújo ${ }^{4}$, \\ Alfredina dos Santos Araújo 5
}

Resumo: Objetivou-se realizar através do processo de secagem convectiva, o reaproveitamento do resíduo da cebola, especificamente a casca, para obtenção do pó, analisando os parâmetros físicos para posterior aplicação como chá. Os pós e chás foram submetidos às caracterizações físicas, químicas e físico-químicas. No tratamento estatístico, empregou-se o delineamento experimental de blocos inteiramente casualizados com 4 tratamentos e 3 repetições, os dados foram submetidos à análise de variância e a comparação de médias foi feita pelo teste de Tukey à $5 \%$ de probabilidade. A casca da cebola apresenta um maior teor de acidez em ácido pirúvico que as amostras secas (pó). As cascas da cebola apresentam uma luminosidade clara, assim como o chá em ambas as temperaturas, observando assim que a mesma não alterou esse parâmetro nas duas formas (casca e chá). A temperatura interferiu de forma satisfatória na casca para os valores de flavonoides, em contrapartida os valores de antocianinas, clorofilas e carotenoides foram insatisfatórios, para os chás, observou-se que os valores de flavonoides, carotenoides, clorofila e antocianinas tiveram um decréscimo e apresentaram uma variação nos valores com a mudança de temperatura. Por conseguinte, pode-se concluir que o uso de diferentes temperaturas de secagem torna-se inviável, sendo que a elaboração do chá com as cascas in natura proporciona a obtenção de teores mais elevados dos componentes.

Palavra-chave: Allium cepa L.; Compostos fenólicos; Infusão

\begin{abstract}
The objective of this work was to perform the reuse of the onion residue, specifically the bark, to obtain the powder through the convective drying process, analyzing the physical parameters for later application as tea. The powders and teas were submitted to the physical, chemical and physico-chemical characterization. In the statistical treatment, the experimental design of completely randomized blocks with 4 treatments and 3 replicates was used, the data were submitted to analysis of variance and the means comparison was done by the Tukey test at $5 \%$ probability. The onion peel has a higher acid content in pyruvic acid than the dry (powder) samples. The onion peels have a clear luminosity, as does tea at both temperatures, noting that it did not change this parameter in the two forms (bark and tea). The temperature interfered satisfactorily in the bark for the flavonoid values; in contrast, the anthocyanins, chlorophylls and carotenoids values were unsatisfactory; for the teas, it was observed that the values of flavonoids, carotenoids, chlorophyll and anthocyanins decreased and presented a change in the values with the change in temperature. Therefore, it can be concluded that the use of different drying temperatures becomes impracticable, and the preparation of the tea with the bark in natura provides the highest levels of the components.
\end{abstract}

Keyword: Allium cepa L.; Phenolic compounds; Infusion

\footnotetext{
*Autor para correspondência

Recebido para publicação em 25/11/2017; aprovado em 20/12/2017

${ }^{1}$ Pós Graduanda em Engenharia Agrícola, Universidade Federal de Campina Grande, Campina Grande, Paraíba, (83) 9 9994-0868, e-mail: alinequimicaindustrial@hotmail.com

${ }^{2}$ Engenheira de Alimentos, Universidade Federal de Campina Grande, Campina Grande, Paraíba, e-mail: deborahealucena@gmail.com

${ }^{3}$ Professora Doutora, Universidade Federal de Campina Grande, Campina Grande, Paraíba , e-mail: ana_trindade@yahoo.com.br

${ }^{4}$ Professor Doutor, Universidade Federal de Campina Grande, Campina Grande, Paraíba, e-mail: gilmartrindade@ufcg.edu.br

${ }^{5}$ Professora Doutora, Universidade Federal de Campina Grande, Pombal, Paraíba UFCG, e-mail: alfredina@ccta.ufcg.edu.br
} 


\section{INTRODUÇÃO}

Uma crescente procura por parte da sociedade vem ocorrendo em busca de uma melhoria na qualidade de vida. A existência da procura por novos produtos alimentícios, principalmente provenientes da natureza, desperta a busca por estudos que promovam tecnologias inovadoras para atender a demanda juntamente com a diminuição de impactos causados pelo setor industrial ao meio ambiente (SIQUEIRA, 2010). Estudos mostraram que são necessárias novas fontes potenciais de alimentos que sejam capazes de suprir as necessidades nutricionais, uma alternativa são as não convencionais, obtidas a partir do aproveitamento de resíduos agrícolas, proporcionando ganhos econômicos e diminuição do impacto ambiental resultante dos descartes (PADILHA et al, 2016).

Como uma grande fonte de resíduos gerados pela agroindústria, têm-se as hortaliças, devido a elevada quantidade de perdas pós colheita, resultante da alta perecividade e da falta de técnicas de produção aplicadas corretamente (MORETTI; DURIGAN, 2002).

De acordo com dados do IBGE (2013), entre as hortaliças, a cebola ocupou, em 2011, no Brasil, o quarto lugar em importância econômica, depois de culturas como tomate, batata e melancia, com um valor de produção de R\$ 900,3 milhões e uma produção total de $1.523 .316 \mathrm{t}$. Associada à alta produção, o Brasil é um dos países que mais consome cebola no mundo, sendo a maior parte comercializada processada ou na forma de temperos (SCHIMITT, 2011).

Agregado à alta produção desta hortaliça, encontra-se um elevado descarte das partes não utilizadas nesse processamento, englobando principalmente como fonte desse resíduo as cascas das cebolas (OLIVEIRA et al, 2016).

Segundo Soares et al. (2004), as cascas das cebolas apresentam uma elevada concentração de compostos fenólicos, que englobam uma grande gama de substâncias com alta influência na qualidade dos alimentos. Desta forma, a inclusão das mesmas como fonte de alimento funcional proporciona um novo perfil para as agroindústrias.

A demanda alimentícia juntamente com a necessidade de uma maior durabilidade do produto, gera o interesse em reinventar os métodos para conservação dos alimentos, adequando tal necessidade aos avanços tecnológicos (GALO et al, 2018). Uma opção totalmente aceita na área alimentícia, é a secagem, que se baseia na redução da água no produto e consequentemente maior vida útil, gerando decaimento do metabolismo, da atividade enzimática, fúngica e bacteriana. A secagem convectiva envolve a aplicação de calor, removendo a umidade e substituindo o ar saturado por ar seco, com um volume especifico mais elevado (NASCIMENTO et al., 2015).

Baseado na escassa linha de pesquisa que busque o reaproveitamento de resíduos como uma fonte alimentícia alternativa, objetivou-se avaliar o efeito da temperatura de secagem da casca de cebola (Allium cepa L.) através do processo convectivo, para a obtenção do pó e futura aplicação do mesmo como chá, analisando os parâmetros físicos, químicos e físico-químicos.

\section{MATERIAL E MÉTODOS}

A pesquisa foi desenvolvida no Laboratório de Engenharia de Alimentos (LEA), do Centro de Tecnologia e Recursos Naturais (CTRN) da Universidade Federal de
Campina Grande (UFCG), Campina Grande, Paraíba. Foram utilizadas cascas de cebolas amarelas oriundas do mercado varejista de Campina Grande, Paraíba.

Para obtenção do pó, inicialmente as cascas das cebolas foram selecionadas de forma criteriosa, visando garantir a homogeneidade, característica física e qualidade do produto final. Em seguida, foram lavadas em água corrente, logo após foram sanitizadas em solução clorada (100 ppm de cloro ativo por $15 \mathrm{~min}$ ) e enxaguadas com água. O procedimento está ilustrado na Figura 1. Após a sanitização, as cascas da cebola foram submetidas à secagem e trituração para obtenção do pó. A casca in natura também foi submetida à trituração. Os pós foram armazenados em embalagens laminadas à temperatura ambiente.

Figura 1. Fluxograma do processamento para produção do pó da casca de cebola.

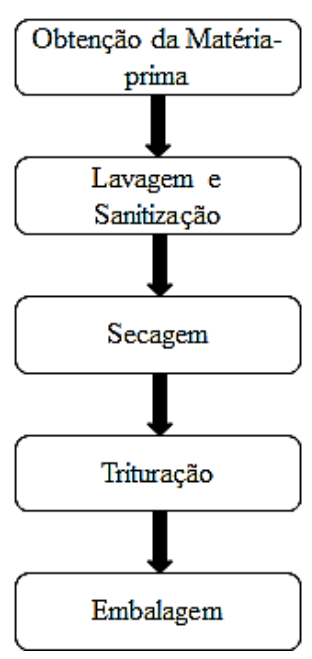

Fonte: Autor, 2016

As amostras depois de sanitizadas foram submetidas à secagem nas temperaturas de $50^{\circ} \mathrm{C}, 60^{\circ} \mathrm{C}$ e $70^{\circ} \mathrm{C}$. Utilizou-se um secador com circulação de ar forçada.

As amostras foram secas por 24 horas. As cascas in natura e desidratadas foram submetidas às análises físicoquímicas de $\mathrm{pH}$, acidez titulável em ácido pirúvico e teor de água, segundo as metodologias descritas no Instituto Adolfo Lutz (IAL, 2008). Todas as análises foram realizadas em triplicata.

As cascas foram submetidas à análise colorimétrica, realizada em espectrofotômetro portátil Hunter Lab Mini Scan XE Plus, modelo 4500 L, obtendo-se os parâmetros L*, $a^{*}$ e $b^{*}$, em que $L^{*}$ define a luminosidade $\left(L^{*}=0\right.$ - preto e $\mathrm{L}^{*}=100-$ branco) e $\mathrm{a}^{*} \mathrm{e} \mathrm{b}^{*}$ são responsáveis pela cromaticidade $\left(+a^{*}\right.$ vermelho e $-a^{*}$ verde; $+b^{*}$ amarelo e $-b^{*}$ azul).

Para a determinação de teores de flavonoides totais, foi utilizado o método colorimétrico com cloreto de alumínio segundo Woisky e Salatino (1998), com absorbância em espectrofotômetro a um comprimento de onda de $425 \mathrm{mn}$.

$\mathrm{Na}$ análise dos parâmetros dos teores de carotenoides e clorofila, se utilizou a metodologia segundo Lichtenthaler (1987), onde foram feitas leituras de absorbância em espectrofotômetro a um comprimento de onda de 470, 646 e $663 \mathrm{mn}$. A determinação de antocianinas foi realizada segundo Francis (1982) utilizando absorbância em espectrofotômetro a um comprimento de onda de $535 \mathrm{mn}$. 
O chá foi produzido por infusão de acordo com procedimentos sugeridos em chás de sachê comercializados. Foi adicionado cerca de $1 \mathrm{~g}$ do pó em papel filtro, onde o mesmo foi mergulhado em 200 mililitros de água a $100^{\circ} \mathrm{C}$ e imerso por um período de 5 minutos. Após a imersão, o chá foi armazenado em garrafas de plástico em câmara frigorífica a $5^{\circ} \mathrm{C}$.

Os chás obtidos foram submetidos às análises de cor, teor de flavonoides, carotenoides, clorofila e antocianinas, utilizando as metodologias descritas anteriormente.

Para as análises físico-químicas, colorimétricas e analíticas foi utilizado o delineamento experimental de blocos inteiramente casualizados com 4 tratamentos e 3 repetições, utilizando-se o software Assistat versão 7.7. beta (SILVA; AZEVEDO,2016). Os dados foram submetidos à análise de variância (ANOVA) e a comparação de médias foi feita pelo teste de Tukey a 5\% de probabilidade.

\section{RESULTADOS E DISCUSSÃO}

Na Tabela 1 observam-se os valores físico-químicos das cascas de cebola antes e depois do processamento. Com relação ao teor de água, pode-se observar que a secagem reduziu o teor de água da casca e que os valores entre as amostras secas em diferentes temperaturas não apresentaram diferença significativa. O teor de água é um parâmetro de grande importância para a preservação do alimento, pois, quanto menor o teor de água, menor a possibilidade de proliferação de microrganismos, assim o alimento tem uma maior durabilidade.

Tabela 1. Físico-química das cascas de cebola antes e depois da secagem

\begin{tabular}{cccccc}
\hline Parâmetros & IN & $50^{\circ} \mathrm{C}$ & $60^{\circ} \mathrm{C}$ & $70^{\circ} \mathrm{C}$ & DMS \\
\hline Teor de & $12,01 \mathrm{a}$ & $3,99 \mathrm{~b}$ & $3,99 \mathrm{~b}$ & $3,40 \mathrm{~b}$ & 1,22 \\
água (\%) & & & & & \\
pH & $3,47 \mathrm{c}$ & $4,26 \mathrm{~b}$ & $4,41 \mathrm{a}$ & $4,21 \mathrm{~b}$ & 0.06 \\
Acidez $^{*}$ & $0,75 \mathrm{a}$ & $0,29 \mathrm{~b}$ & $0,30 \mathrm{~b}$ & $0,14 \mathrm{c}$ & 0,13 \\
\hline
\end{tabular}

IN - casca da cebola in natura; 50,60 e $70^{\circ} \mathrm{C}$ - casca de cebolas secas a temperaturas de $50^{\circ} \mathrm{C}, 60^{\circ} \mathrm{C}$ e $70^{\circ} \mathrm{C}$ respectivamente. DMS - Diferença mínima significativa; Médias seguidas pela mesma letra na coluna não diferem estatisticamente entre si pelo teste de Tukey ao nível de 5\% de probabilidade; ${ }^{\text {ns }}$ - não significativo; $* \mathrm{e}^{* *}$ - significativo respectivamente ao nível de 5 e $1 \%$ de probabilidade. *Acidez em ácido pirúvico.

Os valores de $\mathrm{pH}$ para as amostras secas foram maiores que os da casca in natura, o contrário foi observado nos valores da acidez em que a amostra in natura apresentou maior valor em relação aos valores das cascas secas. Segundo Chitarra e Chitarra (1990) a elevada acidez é desejável para a industrialização das cebolas, uma vez que, sendo essa expressa em porcentagem do ácido pirúvico e esse utilizado para medir grau de pungência (sabor e aroma).

O mesmo ocorre com a casca de modo que o valor encontrado para a casca in natura é mais elevado que o encontrado por Schunemann et al. (2006) no bulbo da cebola, de $0,17-0,27 \%$. As cascas secas nas temperaturas de $50{ }^{\circ} \mathrm{C}$ e $60^{\circ} \mathrm{C}$, não apresentaram diferença estatística, porém observase que o aumento da temperatura acarretou a diminuição do valor da acidez. Assim, é possível observar que a casca apresenta uma maior pungência com relação ao bulbo, sendo essa pungência perdida com a secagem.
Os valores das análises colorimétricas verificam-se na Tabela 2, em que todas as amostras apresentaram uma luminosidade clara, valores mais próximos de 100 que de 0 e sendo a amostra in natura mais clara que as demais.

Assim, todo o processo pelo qual as cascas passaram, da sanitização à secagem, alteraram na luminosidade das cascas, observando-se ainda que a luminosidade aumenta de acordo com o aumento da temperatura de secagem, sendo o mesmo observado na secagem de casca de mandioca por Vilhalva et al. (2012), em que as suas amostras apresentaram uma tendência mais clara com o aumento da temperatura.

Tabela 2. Colorimetria da casca de cebola

\begin{tabular}{cccccc}
\hline Parâmetros & IN & $50^{\circ} \mathrm{C}$ & $60^{\circ} \mathrm{C}$ & $70^{\circ} \mathrm{C}$ & DMS \\
\hline $\mathrm{L}^{*}$ & $61,74^{\mathrm{a}}$ & $58,18^{\mathrm{d}}$ & $58,53^{\mathrm{c}}$ & $60,20^{\mathrm{b}}$ & 0,15 \\
$\mathrm{a}^{*}$ & $9,58^{\mathrm{a}}$ & $7,83^{\mathrm{d}}$ & $8,92^{\mathrm{b}}$ & $8,19^{\mathrm{c}}$ & 0,07 \\
$\mathrm{~b}^{*}$ & $26,47^{\mathrm{d}}$ & $27,63^{\mathrm{c}}$ & $28,89^{\mathrm{b}}$ & $29,37^{\mathrm{a}}$ & 0,22 \\
\hline
\end{tabular}

IN - casca da cebola in natura; 50,60 e $70^{\circ} \mathrm{C}$ - casca de cebolas secas a temperaturas de $50^{\circ} \mathrm{C}, 60^{\circ} \mathrm{C}$ e $70^{\circ} \mathrm{C}$ respectivamente. DMS - Diferença mínima significativa; Médias seguidas pela mesma letra na coluna não diferem estatisticamente entre si pelo teste de Tukey ao nível de $5 \%$ de probabilidade; ${ }^{\text {ns }}$ - não significativo; $* \mathrm{e}^{* *}$ - significativo respectivamente ao nível de 5 e $1 \%$ de probabilidade.

Para o parâmetro de cromaticidade $\mathrm{a}^{*}$, pode-se observar que as cascas obtiveram uma coloração para o vermelho, pois apresentaram valores positivos, sendo que a amostra in natura apresentou uma coloração maior. Em relação ao parâmetro de cromaticidade $b^{*}$, o resultado foi o esperado, confirmando a coloração amarela.

Na Tabela 3 nota-se os valores das análises de flavonoides, carotenoides, clorofila e antocianinas da casca da cebola. Para os valores de flavonoides pode-se observar que a casca in natura e as secas a $50^{\circ} \mathrm{C}$ e $70^{\circ} \mathrm{C}$ não apresentaram diferença significativa.

Analisando a amostra seca a $60^{\circ} \mathrm{C}$, houve uma diminuição de aproximadamente $0,84 \%$ com as demais amostras e, assim, a temperatura não interferiu na concentração de flavonoides. Ko et al. (2011) encontrou valores de flavonoides entre 16,29 e 17,63 para a casca da cebola, valores menores que o encontrado nesse trabalho.

Albishi et al. (2013) encontraram valores semelhantes, de 19,64, também para casca de cebola. Segundo Kang et al. (1998a) a quercetina é 77 vezes mais abundante na intragável parte (casca) que na parte comestível do material da cebola.

Tabela 3. Flavonoides, carotenoides, clorofila e antocianinas em casca da cebola.

\begin{tabular}{cccccc}
\hline Parâmetros & IN & $50^{\circ} \mathrm{C}$ & $60^{\circ} \mathrm{C}$ & $70^{\circ} \mathrm{C}$ & DMS \\
\hline $\begin{array}{c}\text { Flavonoides } \\
(\mathrm{mg} / \mathrm{g}\end{array}$ & $19,08 \mathrm{a}$ & $19,06 \mathrm{a}$ & $18,96 \mathrm{~b}$ & $19,12 \mathrm{a}$ & 0,07 \\
$\begin{array}{c}\text { quercetina }) \\
\text { Carotenoides } \\
(\mu \mathrm{g} / \mathrm{g})\end{array}$ & $0,52 \mathrm{a}$ & $0,36 \mathrm{c}$ & $0,43 \mathrm{~b}$ & $0,45 \mathrm{~b}$ & 0,02 \\
$\begin{array}{c}\text { Clorofila } \\
(\mu \mathrm{g} / \mathrm{g})\end{array}$ & $1,96 \mathrm{a}$ & $1,34 \mathrm{~d}$ & $1,62 \mathrm{c}$ & $1,79 \mathrm{~b}$ & 0,004 \\
$\begin{array}{c}\text { Antocianinas } \\
(\mathrm{mg} / 100 \mathrm{~g})\end{array}$ & $4,62 \mathrm{a}$ & $4,53 \mathrm{a}$ & $3,59 \mathrm{~b}$ & $3,22 \mathrm{c}$ & 0,22 \\
\hline
\end{tabular}

IN - casca da cebola in natura; 50,60 e $70^{\circ} \mathrm{C}$ - casca de cebolas secas a temperaturas de 50,60 e $70^{\circ} \mathrm{C}$ respectivamente. DMS - Diferença mínima significativa; Médias seguidas pela mesma letra na coluna não diferem estatisticamente entre si pelo teste de Tukey ao nível de 5\% de probabilidade; ns - não significativo; * $\mathrm{e}^{* *}$ - significativo respectivamente ao nível de 5 e $1 \%$ de probabilidade. 
Observa-se ainda que os valores de carotenoides e clorofila diminuíram quando submetidos à secagem. Segundo Maldonado-Robledo et al. (2003), os carotenoides são responsáveis pelas cores do amarelo ao vermelho de frutas, vegetais, fungos e flores e, assim, pode-se observar que as amostras que tiveram uma maior intensidade de amarelo $\left(b^{*}\right)$ e vermelho $\left(\mathrm{a}^{*}\right)$ apresentaram um valor maior de carotenoides.

Apesar das cascas não apresentarem coloração verde, obtiveram valores para clorofila, mesmo em pequena quantidade. Para as amostras secas houve um aumento com o aumento da temperatura.

Os valores de antocianinas diminuíram com o aumento da temperatura. No reino vegetal, as antocianinas são pigmentos responsáveis por uma variedade de cores que variam do vermelho vivo ao violeta e azul (BOBBIO \& BOBBIO, 1995). A casca da cebola não apresenta, visivelmente, essas colorações, mas na análise colorimétrica foi observada uma intensidade da cor vermelha e, por isso, foi possível obter valores para as antocianinas, entretanto, são valores inferiores ao encontrado em outros produtos de coloração visivelmente vermelha ao violeta, como por exemplo, na acerola, onde Lima et al. (2002) encontrou valores de 26,23 mg e 14,11 mg.

$\mathrm{Na}$ Tabela 4 encontram-se os valores da análise colorimétrica dos chás. É possível observar que os chás apresentaram luminosidade um pouco acima de 50 sendo, portanto, claras. Os valores não apresentaram uma ordem, a amostra $50^{\circ} \mathrm{C}$ obteve valor de 52,79 , maior que os demais, a amostra $70^{\circ} \mathrm{C}$ apresentou uma maior luminosidade que a amostra in natura e a de $60^{\circ} \mathrm{C}$.

Tabela 4. Colorimetria dos chás da casca de cebola

\begin{tabular}{cccccc}
\hline Parâmetros & IN & $50{ }^{\circ} \mathrm{C}$ & $60{ }^{\circ} \mathrm{C}$ & $70^{\circ} \mathrm{C}$ & DMS \\
\hline $\mathrm{L}^{*}$ & $50,7 \mathrm{c}$ & $52,79 \mathrm{a}$ & $50,53 \mathrm{~d}$ & $50,92 \mathrm{~b}$ & 0,08 \\
$\mathrm{a}^{*}$ & $-1,43 \mathrm{~b}$ & $-3,01 \mathrm{a}$ & $-1,14 \mathrm{c}$ & $-1,51 \mathrm{~b}$ & 0,09 \\
$\mathrm{~b}^{*}$ & $15,7 \mathrm{c}$ & $9,08 \mathrm{~d}$ & $16,9 \mathrm{a}$ & $16,3 \mathrm{~b}$ & 0,14 \\
\hline
\end{tabular}

IN - casca da cebola in natura; 50,60 e $70^{\circ} \mathrm{C}$ - casca de cebolas secas a temperaturas de 50,60 e $70^{\circ} \mathrm{C}$ respectivamente. DMS - Diferença mínima significativa; Médias seguidas pela mesma letra na coluna não diferem estatisticamente entre si pelo teste de Tukey ao nível de 5\% de probabilidade;

ns - não significativo; * $\mathrm{e}^{* *}$ - significativo respectivamente ao nível de $5 \mathrm{e}$ $1 \%$ de probabilidade.

Os valores de $a^{*}$ se apresentaram negativos, assim, as amostras obtiveram uma coloração verde, apresentando a amostra $50^{\circ} \mathrm{C}$ uma maior intensidade. Para o parâmetro b*, os valores se apresentaram positivos, sendo de coloração amarela. Pode-se observar que as amostras que apresentam uma maior intensidade de verde obtiveram uma menor intensidade de amarelo.

$\mathrm{Na}$ Tabela 5 observa-se valores de flavonoides, carotenoides, clorofila e antocianinas para os chás obtidos a partir das cascas da cebola. Pode-se verificar que os valores apresentaram um decréscimo com relação aos pós. Para os valores de flavonoides, o chá com a casca in natura apresentou um valor maior que as cascas secas, sendo que as cascas secas em diferentes temperaturas não apresentaram diferença significativa entre si.
Tabela 5. Flavonoides, carotenoides, clorofila e antocianinas dos chás da casca da cebola

\begin{tabular}{cccccc}
\hline Parâmetros & IN & $50^{\circ} \mathrm{C}$ & $60^{\circ} \mathrm{C}$ & $70^{\circ} \mathrm{C}$ & DMS \\
\hline $\begin{array}{c}\text { Flavonoides } \\
(\mathrm{mg} / \mathrm{g} \text { quercetina }) \\
\text { Carotenoides } \\
(\mu \mathrm{g} / \mathrm{g})\end{array}$ & $2,86 \mathrm{a}$ & $1,28 \mathrm{~b}$ & $1,27 \mathrm{~b}$ & $1,23 \mathrm{~b}$ & 0,05 \\
$\begin{array}{c}\text { Clorofila }(\mu \mathrm{g} / \mathrm{g}) \\
\text { Antocianinas } \\
(\mathrm{mg} / 100 \mathrm{~g})\end{array}$ & $0,25 \mathrm{c}$ & $0,12 \mathrm{~d}$ & $0,25 \mathrm{~b}$ & $0,33 \mathrm{a}$ & 0,003 \\
\hline
\end{tabular}

IN - casca da cebola in natura; $50^{\circ} \mathrm{C}, 60^{\circ} \mathrm{C}$ e $70^{\circ} \mathrm{C}$ - casca de cebolas secas a temperaturas de $50^{\circ} \mathrm{C}, 60^{\circ} \mathrm{C}$ e $70^{\circ} \mathrm{C}$ respectivamente. DMS - Diferença mínima significativa; Médias seguidas pela mesma letra na coluna não diferem estatisticamente entre si pelo teste de Tukey ao nível de 5\% de probabilidade; ${ }^{\text {ns }}$ - não significativo; $* \mathrm{e}^{* *}$ - significativo respectivamente ao nível de 5 e $1 \%$ de probabilidade.

Verifica-se ainda que os valores de carotenoides do chá com a casca seca a $70^{\circ} \mathrm{C}$ apresentaram um maior valor com relação as demais. O mesmo não aconteceu para os valores de clorofila, pois, a amostra com a casca in natura apresentou um maior valor e pode-se observar que os valores de clorofila não se correlacionaram com os valores do parâmetro $a^{*}$ (coloração verde). Já para os valores de antocianinas, o mesmo foi observado para os carotenoides.

Assim, para os valores de flavonoides e clorofila, foi possível observar que a amostra in natura apresentou uma maior facilidade de migração desses compostos para a água. Já para os valores de carotenoides e antocianinas o mesmo comportamento foi observado para a amostra seca à temperatura de $70^{\circ} \mathrm{C}$.

\section{CONCLUSÕES}

A aplicação de diferentes temperaturas de secagem na casca da cebola ocasionou uma redução dos parâmetros analisados, desta forma, torna-se mais viável a elaboração do chá com as cascas in natura uma vez que o mesmo apresentou componentes com teores mais elevados.

\section{REFERÊNCIAS}

ALBISHI, T.; JOHN, J. A.; AL-KHALIFA, A. S.; SHAHIDI, F. Antioxidative phenolic constituents of skins of onion varieties and their activities. Journal of functional foods. v. 5, p. 1991-1203, 2013.

BISPO, R. C.; QUEIROZ, S. O. P.; OLIVEIRA, G. M.; CARVALHO, A. R. P.; FLORES, D. S. "Desempenho agronômico de cultivares de cebola sob diferentes tensões de água no solo.” Irriga, v. 22, n. 3, p. 485-496.

BOBBIO, P. A.; BOBBIO, F. O. Pigmentos naturais. In: BOBBIO, P. A.; BOBBIO, F. O.(Ed.) Introdução à Química de Alimentos. $2^{a}$ ed., São Paulo: Varela, 1995. cap.6, p.191223.

CHITARRA, M. I. F.; CHITARRA, A. B. Pós-colheita de frutos $\mathrm{e}$ hortaliças: fisiologia $\mathrm{e}$ manuseio. Lavras: ESAL/FAEPE, p. 293, 1990. 
FRANCIS, F. J. Analysis of anthocyanins. In MARKAKIS, P. Anthocyanins as Food Colors. New York, pp. 182-205, 1982.

GALO, G. T.; LIMA, A. C. S.; MACHADO, K. M.; VIEIRA, L. B.; MARTINS, V. C.; FERREIRA, N. L.; LUCARINI, A. C.'Estudo da extração da quercetina a partir da cebola roxa (Allium ceppa L.) e seu uso como conservante alimentar natural." The Journal of Engineering and Exact Sciences, v. 4, n., p 0153-0162, 2018.

INSTITUTO ADOLFO LUTZ, IAL. Normas Analíticas do Instituto Adolfo Lutz: métodos físicos e químicos para análise de alimentos. Digital. I.A.L., 4.ed, 1.ed., São Paulo, 2008.

IBGE. Indicadores IBGE 2013. Disponível em: <ftp://ftp.ibge.gov.br/Producao_Agricola/Fasciculo_Indicador es_IBGE/2013/estProdAgr_201309.pdf >.Acesso em: 02 set 2015.

KANG, S., KIM, Y., HYUN, K., KIM, Y., SONG, B., SHIN, S., PARK, Y. Development of separating techniques on quercetin-related substances in onion (Allium cepa L.). 1. Contents and stability of quercetin-related substances in onion. Journal of the Korean Society of Food Science and Nutrition. v. 27, pp. 682-686, 1998.

KO, M. J.; CHEIGH, C. I.; CHO, S. W.; CHUNG, M. S. Subcritical water extraction of flavonol quercetin from onion skin. Journal of Food Engineering. v. 102, pp. 327-333, 2011. LICHTENTHALER, H. K. Chorophylls and carotenoids: pigment photosynthetic biomembranes. Methods enzymol., San Diego, v. 148, pp. 362-385, 1987.

LIMA, V. L. A. G; MÉLO, E. A.; LIMA, L. S.; LIMA, D. E. S. Polpa congelada de acerola: efeito da temperatura sobre os teores de antocianinas e flavonóis totais. Rev. Bras. Frutic. Jaboticabal - SP, v. 24, n. 3, p. 669-670, dez. 2002.

MALDONADO-ROBLEDO, G.; RODRIGUEZBUSTAMANTE, E.; SANCHEZ-CONTRERAS, A.; RODRIGUEZ-SONOJA, R.; SANCHEZ, S.; Production of tobacco aroma from lutein. Specific role of the microorganisms involved in the process. Applied Microbiology e Biotechnology, v. 62, pp. 484-488, 2003.

MORETTI, C.L; DURIGAN, J.F. Processamento de cebola. Informe Agropecuário, v.23, n. 218, pp. 99-104, 2002.

NASCIMENTO, V. R. G.; BIAGI J.; OLIVEIRA, R. A. "Modelagem matemática da secagem convectiva com radiação infravermelha de grãos de Moringa oleífera". Revista Brasileira Engenharia Agrícola Ambiental, v. 19, n. 7, p. 686-692, 2016.

OLIVEIRA, R. A.; SOUZA, M.; KUTZ, C.; BRUNETTO, G.; COMIN, J. J. "Produção de matéria seca de plantas de cobertura de inverno e rendimento de cebola ao longo de cinco anos sob Sistema de Plantio Direto Agroecológico." Caderno de Agroecologia, v. 10, n.3, 2016.

PADILHA, M. D. R. F; SHINOHAAR N. K. S.; OLIVEIRA, F. H. P. C.; SILVA, S. M.; MATSUMOTO, M. "Alimentos elaborados com partes não convencionais: avaliação do conhecimento da comunidade a respeito do assunto. " Anais de Academia Pernambucana de Ciência Agronômica, v. 11, p.216-225, 2016.

SILVA, F. A. S.; AZEVEDO, C. A. V. The Assistat Software Version 7.7 and its use in the analysis of experimental data. Afr. J. Agric. Res, v.11, n.39, p.3733-3740, 2016.

SIQUEIRA, M. P.; Composição química e atividade biológica de resíduos agroindustriais. Dissertação de mestrado. Universidade de São Paulo. 2010.

SCHIMITT, R. D. Cebola. Síntese Anual da Agricultura de Santa Catarina - 2010-2011. Disponível em: <http://cepa.epagri.sc.gov.br/Publicacoes/Sintese_2011/Cebol a\%20sintese\%202011.pdf>. Acesso em: 02/09/2015.

SCHUNEMANN, A. P.; TREPTOW, R.; LEITE, D. L.; VENDRUSCOLO, J. L. Pungência e características químicas em bulbos de genótipos de cebola (Allium cepa L.) cultivados no alto Vale do Itajaí, SC, Brasil. R. Bras. Agrociência, Pelotas, v. 12, n. 1, pp. 77-80, jan-mar, 2006.

SOARES, V. L.; FINGER, F. L.; MOSQUIM, P. R. Influência do Genótipo e do Estádio de Maturação na Colheita sobre a Matéria Fresca, Qualidade e Cura dos Bulbos de Cebola. Horticultura Brasileira, Brasília, v. 22, n. 1, pp. 18-22, 2004.

VILHALVA, D. A. A.; JÚNIOR, M. S. S.; CALIARI, M.; SILVA, F. A. Secagem convencional de casca de mandioca proveniente de resíduos de indústria de amido. Pesq. Agropec. Trop., Goiânia, v. 42, n. 3, pp. 331-339, jul/set 2012.

WOISKY, R.; SALATINO, A. Analysis of propolis: some parameters and procedures for chemical quality control. J. Apic. Res. v. 37, pp. 99-105, 1998. 